\title{
Intracranial depth electrodes implantation in the era of image-guided surgery
}

\author{
Ricardo Silva Centeno', Elza Márcia Targas Yacubian', \\ Luis Otávio Sales Ferreira Caboclo', Henrique Carrete Júnior², \\ Sérgio Cavalheiro ${ }^{1}$
}

\begin{abstract}
The advent of modern image-guided surgery has revolutionized depth electrode implantation techniques. Stereoelectroencephalography (SEEG), introduced by Talairach in the 1950s, is an invasive method for three-dimensional analysis on the epileptogenic zone based on the technique of intracranial implantation of depth electrodes. The aim of this article is to discuss the principles of SEEG and their evolution from the Talairach era to the image-guided surgery of today, along with future prospects. Although the general principles of SEEG have remained intact over the years, the implantation of depth electrodes, i.e. the surgical technique that enables this method, has undergone tremendous evolution over the last three decades, due the advent of modern imaging techniques, computer systems and new stereotactic techniques. The use of robotic systems, the constant evolution of imaging and computing techniques and the use of depth electrodes together with microdialysis probes will open up enormous prospects for applying depth electrodes and SEEG both for investigative use and for therapeutic use. Brain stimulation of deep targets and the construction of "smart" electrodes may, in the near future, increase the need to use this method.
\end{abstract}

Key words: epilepsy, stereoelectroencephalography, depth electrode, image-guided surgery.

\section{A implantação de eletrodos de profundidade na era da cirurgia guiada por imagem}

\section{RESUMO}

O advento das modernas técnicas de cirurgia guiadas por imagem revolucionaram a técnica de implantação dos eletrodos de profundidade (EP). A estereoeletroencefalografia (E-EEG), conforme introduzida na década de 50 por Talairach, é um método invasivo de análise tridimensional da zona epilpeptogênica, baseado na técnica de implantação intracraniana de EP. O objetivo deste artigo é discutir os princípios da E-EEG e sua evolução, desde a era Talairach até a era atual, da cirurgia guiada por imagem, e suas perspectivas futuras. Embora os princípios gerais da E-EEG tenham permanecidos intactos ao longo dos anos, a implantação de EP, que é a técnica cirúrgica que viabiliza este método, sofreu grande evolução ao longo das últimas três décadas devido ao advento das modernas técnicas de imagem, de sistemas de computação e das novas técnicas estereotáxicas. O uso de sistemas robotizados, a evolução constante das técnicas de

Correspondence Ricardo Silva Centeno Av. Ibirapuera 2907 / cj 415 04028-000 São Paulo SP - Brasil E-mail: ricardo_centeno@isic.org

Support

FAPESP / CNPQ

Received 29 July 2010

Received in final form 21 February 2011 Accepted 9 March 2011 imagem e computação e a utilização de EP com sondas para micro diálise associados a si, abre no futuro uma enorme perspectiva para a aplicação dos EP e da E-EEG, tanto para uso investigativo como terapêutico. A estimulação cerebral de alvos profundos e a fabricação de eletrodos "inteligentes", poderão incrementar, num futuro próximo, a necessidade do uso deste método.

Palavras-chave: epilepsia, estereoeletroencefalografia, eletrodo profundo, cirurgia guiada por imagem.

'Department of Neurology and Neurosurgery, Federal University of São Paulo (UNIFESP), São Paulo SP, Brazil; ${ }^{2}$ Department of Imaging Diagnostic, Federal University of São Paulo (UNIFESP), São Paulo SP, Brazil. 
Indications for epilepsy surgery depend on convergence between the results from examinations that have been performed, and this is of great importance for surgical prognoses. Convergence between the results from noninvasive preoperative investigations, particularly imaging and video-EEG examinations, does not always occur. Semi-invasive or invasive techniques for recording seizures often have to be used, in an attempt to resolve uncertainties. From an electrographic point of view, the ideal would be to make the recording as close as possible to the likely epileptogenic zone. This approach can be accomplished through semi-invasive techniques such as the use of foramen-ovale electrodes, which are indicated only when there are doubts regarding laterality in cases of mesial temporal lobe epilepsy; or through invasive techniques such as the use of subdural electrode arrays or depth electrodes. The latter are the instruments used for performing stereoelectroencephalography (SEEG), which is an invasive technique for recording seizures with the aim of achieving three-dimensional analysis of the epileptogenic zone.

In the 1950s, Talairach and Bancaud ${ }^{1}$ were the first to indicate that the cortical regions involved in epileptic processes could be defined particularly by recording spontaneous seizures. They drew up the complete method named SEEG so that, using anatomical-electroclinical correlations, they would be able to identify the extent of the cortical areas that were involved primarily in ictal discharges, which they defined as the "epileptogenic zone". Their aim was thus to plan cortical resection procedures that would be appropriate for each particular case. The implantation strategy was very much individualized and depended on each patient's clinical, neurophysiological and anatomical characteristics, in a way that therefore distinguished it from other, similar procedures with standardized targets and paths.

In this technique, in a three-dimensional analysis model for the epileptogenic zone, the depth electrodes are inserted going towards deep targets, with intermediate contacts in the cortical and subcortical regions. Therefore, the name "depth electrode" is not adequate as used in defining SEEG, because this technique allows anatomical structures at deep, intermediate and superficial levels to be addressed ${ }^{2}$.

This type of approach is currently used in presurgical assessments in different epilepsy surgical centers in Europe $^{3-5}$, North America ${ }^{6-8}$ and Asia ${ }^{9}$.

The first successful attempts to record intracerebral electrical activity date from the first half of last century. Over those decades, during which the technique for intraoperative recording of signals from the cerebral cortex of epileptic patients was developed by Penfield and Jasper $^{10}$, intracranial electrodes started to be implanted with the aim of recording subcortical structures, mainly with the aim of elucidating the role of basal nuclei in seizures of "petit mal"11,12 and in presumed cases of "centrencephalic" seizures ${ }^{13,14}$. In several studies, the electrodes were implanted freehand, using a technique that resulted in great imprecision in attempting to reach the intracranial targets ${ }^{15,16}$. Moreover, despite the tendency towards using chronic records, the monitoring had the primary aim of inserting intracranial electrodes to record interictal discharges, following the same concepts as established for intraoperative electrocorticography.

The introduction of stereotactic methods for segmentation of intracranial structures and the introduction of the epileptogenic zone concept were fundamental for the methodological development of presurgical assessments on patients with epilepsy.

Stereotactic devices for human use were designed by Spiegel and Wycis in $1947^{17}$, and their use for recording deep cerebral structures started to be mentioned in $1950^{18}$. Stereotactic implantation of intracranial electrodes gained popularity and was mentioned as part of the evaluation of temporal lobe epilepsy at the beginning of the $1960 \mathrm{~s}^{19}$. Meanwhile, in the Neurosurgical Unit of Hospital Saint-Anne, in Paris, stereotactic investigations using intracranial electrodes in epileptic patients were inspired by a recently elaborated new concept: epileptic seizures were considered to be a dynamic process with temporal-spatial organization that was sometimes multidirectional and could be better defined as a three-dimensional arrangement ${ }^{20-23}$. The location of origin and primary organization of this dynamic process in focal epilepsy, which, if removed, would result in controlling the crisis, was defined as the epileptogenic zone.

Following these premises, the Saint-Anne group developed the SEEG methodology ${ }^{24,25}$, such that it would become possible to achieve the complex requirements of defining the organization of the ictal discharges in threedimensional space and time. These procedures had the aim of investigating a coherent and previously formulated hypothesis regarding the epileptogenic zone that would be based on anatomical and electroclinical findings that were particular to each case. For these purposes, several prerequisites would have to be attained: the electroclinical definition of the epilepsies should be based on recordings of spontaneous seizures, and not be limited to interictal static electrical abnormalities; the structures that were previously assumed to be involved in the ictal beginnings and in the primary and secondary organization of the ictal discharges would need to be previously established and included in the exploration area, and would need to be reached with the precision of stereotactic techniques; differing from previous studies on intracranial electrodes, the primary aim in this pro- 
cedure was to explore the cortical structures, given that it was presumed that the dynamic organization of the ictal discharges would follow cortical pathways. For this last proposition, because of the variability of the cortical anatomy between individuals, the stereotactic localization of different cortical areas demanded an approach based on a statistically constructed proportional reference system that would use the intercommissural line, as identified using contrasted ventriculography, as the reference basis. This method made it possible to incorporate each patient's anatomy in an anamorphous and flexible reference system ${ }^{26}$.

Furthermore, stereotactic and stereoscopic teleangiography provide an excellent definition of the anatomy of the cerebral gyri and sulci $i^{27,28}$, thereby making it possible to plan avascular paths for placement of electrodes by means of a double grid mounted on a Talairach stereotactic halo, which was manufactured commercially ${ }^{29}$.

Since the pioneering experience of the Paris group, modern neuroradiology and image merging techniques have progressively developed and increased the safety of the method and the target-reaching precision, by means of stereotactic direction-finding in intracranial structures $^{30,31}$. However, the basic concept of a single "stereotactic environment", in which electrophysiological, morphological and functional information can be imported and entered in a dynamic correlation process for defining the three-dimensional organization of an epileptic discharge, is still of prime importance within the current era of stereoelectroencephalography, and has been of relevance for the development of modern epilepsy surgery and stereotactic neurosurgery $y^{32,33}$.

There are many scenarios within which depth electrodes have been proven to be useful, but the extent and frequency of their use vary from one institution to another (Table).

There are several techniques for implanting depth electrodes, and these include the use of a stereotactic halo, neuronavigation without a stereotactic halo, freehand and with endoscopic assistance. Implantation of electrodes using a stereotactic halo is already well established and used in a large number of centers. Several systems are available on the market, such as the Brown-
Roberts-Wells (BRW), Cosman-Roberts-Wells (CRW) and Leksell systems, among others.

Freehand implantation of depth electrodes has been reported to have acceptable accuracy ${ }^{34}$. However, this is not a viable technique for longitudinal implantation of electrodes in the hippocampus and, theoretically, there is a greater risk of hemorrhage given that the vessels along the path cannot be viewed. On the other hand, this method reduces the duration of the operation and the need for additional images.

The system without a stereotactic halo (known as a frameless system) can be used with the same precision and safety as provided by the conventional system with a halo, thereby making the procedure faster and more practical ${ }^{35,36}$.

Thus, the image acquisition can be done at any time during the preoperative period, without the need to acquire the images on the day of the surgery, with the halo, as in the conventional system. In this way, the surgical planning can be done before the patient is brought to the surgical center, thereby making it possible to start work on the case quickly on the day of the operation.

By using a pair of mechanical stabilizer arms, electrodes can be implanted simultaneously on both sides of the head, by two different neurosurgeons, thereby halving the time taken for implantation. This system also provides greater flexibility in the work area during the operation, both for craniotomy construction and for the trepanation points, for implanting the electrodes in the cranium, given that there is no interposition of a stereotactic halo. Moreover, application of a stereotactic halo may be very stressful for the patient, which obviously is avoided in this type of implantation.

Finally, Song et al. ${ }^{37}$ described a method for longitudinal implantation of electrodes in which the system without a stereotactic halo was combined with neuronavigation guidance using neuroendoscopy. Through the stereotactic system, a path that places the endoscope in the lateral ventricular atrium is established. Next, with endoscopic viewing, the electrode is placed on the temporal horn, along the axis of the hippocampus, without penetrating the cerebral tissue. In this method, because the electrode does not penetrate the tissue of the hippocampus, it provides the advantage of not causing le-

Table. Common scenarios in which depth electrodes have proven to be useful.

\begin{tabular}{ll}
\hline Type of study & Structures explored \\
\hline Studies on frontal lobes & Anterior cingulum, orbitofrontal region and supplementary motor area \\
Studies on temporal lobes & Hippocampus and amygdale \\
Reoperation studies & Areas in which adherences make recordings with subdural striae impossible \\
Deep lesions & Hypothalamic hamartomas and periventricular heterotopias \\
\hline
\end{tabular}




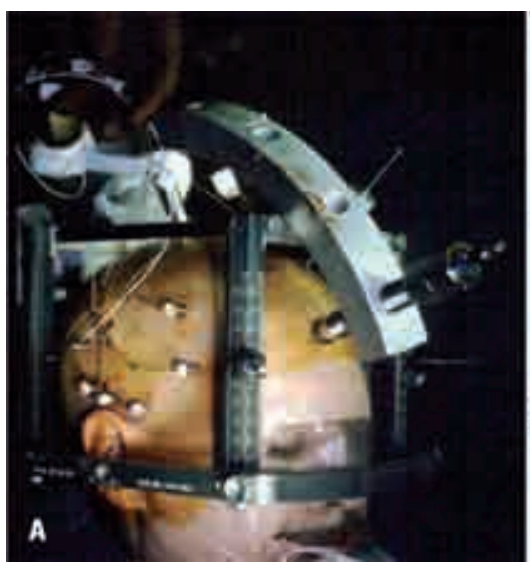

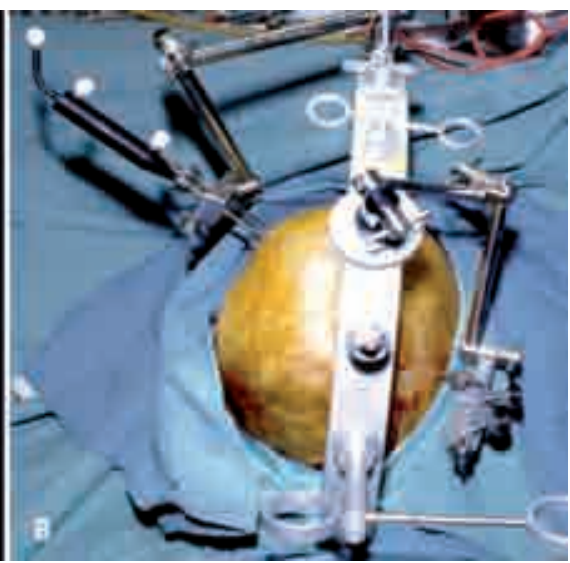

Figure. Evolution of the stereotactic system for implantation of the depth electrodes. [A] Use of stereotactic halo. [B] Use of "frameless" system with bilateral mechanical arms. sions in the hippocampus, which will not be resected. Although the clinical significance of this remains unknown, it seems evident that this theoretically confers an advantage on this method, over the others.

While maintaining the basic principles as developed by Talairach and Bancaud ${ }^{1}$, SEEG underwent adaptations as stereotactic, computational and imaging techniques evolved over the years, with successive incorporation of digital subtraction angiography, magnetic resonance imaging and positron emission tomography into the stereotactic methods for cerebral mapping. Although it was initially performed by implanting electrodes with the aid of a stereotactic halo, it has evolved to the present-day use of stereotactic techniques guided by neuronavigation, which does away with the need to use a stereotactic halo (i.e. becoming a frameless system).

Thus, at the start of the 1980s, tomography and digital angiography were used to locate targets, in order to implant the electrodes. From the second half of the 1980s, magnetic resonance imaging replaced tomography and, in the middle of the 1990s, digital angiography (a semiinvasive method that involves puncturing the femoral artery) was replaced by digital angiographic imaging by means of magnetic resonance, through administration of a double dose of gadolinium. This last noninvasive method, which is performed by means of puncturing a peripheral vein, enables three-dimensional analysis on the cerebral blood vessels. To simplify the method and improve its accuracy, neuronavigation systems were also introduced at that time. Over the course of these advances, during the 1990s, the implantation of electrodes (which until then had been done using a stereotactic halo) started to be performed by means of stereotactic system with an articulated arm that enabled support for the electrodes (known as a free guide and computer-assisted frameless device), which was assisted by neuronavigation without the use of a stereotactic halo (Figure).

The efficacy of invasive monitoring using SEEG has remained constant over the years, but the evaluation of this efficacy has been based on different criteria. Guenot et al. $^{3}$ and Almeida et al. ${ }^{38}$ used the capacity of SEEG to provide critical information that would support or contraindicate surgery, as the criterion for evaluating the efficacy of the procedure, without taking into consideration the surgical results from patients operated after performing SEEG. Through this method, they considered that SEEG was effective in $84 \%$ and $96 \%$ of the cases, respectively.

On the other hand, other authors have considered that, in order to justify the use of invasive monitoring, there would have to be a substantial number of patients with epileptogenic foci that could be located, and who would present excellent crisis control after the resection. Using these criteria, the surgical results from different centers (with different depth electrode implantation techniques) were compiled in a study ${ }^{39}$ that showed that $44 \%$ of the results were completely seizure-free. This proportion was not in line with the much more favorable results obtained among patients who underwent operations after noninvasive assessments. These findings therefore probably reflect the particular complexity of patients who require intracranial monitoring.

The efficiency and the morbidity-mortality from implantation of depth electrodes using the frameless system guided by neuronavigation and the conventional system using a stereotactic halo are similar.

The morbidity rate reported by centers that use depth electrodes ranges from $1 \%$ to $5 \%$ 3,35,36,40-44, and such cases almost always fall into two categories: hemorrhage or infection. Certain measures are important for preventing these two principal complications. Suspension of the use of non-steroidal anti-inflammatory drugs and asking for tests to check the duration of bleeding among patients who are taking valproic acid, prior to the operation, may reduce the risk of bleeding. In addition, the use of specific surgical techniques may reduce this risk, such as 
the use of a trepanation orifice instead of small orifices of the diameter of the electrodes, made using a drill, and viewing of the path of the electrode from the entry point on the cortical surface down to the target, free of large vessels, accessed by means of neuronavigation imaging. Finally, limitation of the number of electrodes to those that are really necessary reduces the number of times that electrodes are passed through the brain and thus reduces the risk of hemorrhage.

Some institutions use intravenous or oral antibiotics for their patients during the electrode implantation period. However, there are no convincing data to support this practice ${ }^{45}$, given that a large number of centers only use antibiotics during the operation and withdraw this medication 24 hours after the operation. Others do not even use antibiotics ${ }^{46}$. Another technique that reduces the infection rate is care regarding the exit point for the electrode on the skin. An electrode exit point through a counter-opening in the skin, several centimeters from the electrode entry point in the cranium, with purse stitches around the exit, reduces the risk of a cerebrospinal fluid fistula. The great majority of infections are successfully treated by removing the electrode, together with the use of intravenous antibiotics. Cerebritis and abscesses are extremely rare ${ }^{47}$. Two cases of CreutzfeldtJakob disease have been reported ${ }^{48}$, and it is therefore important to avoid reuse of electrodes.

Although extremely rare, there are reports from some series regarding patients who died because of implantation of depth electrodes ${ }^{43}$.

More recently, some cases of the use of depth electrodes for therapeutic purposes, causing lesions through thermocoagulation, have been described in the literature. These can be used in patients with a limited epileptogenic zone that is well confined to the region of one electrode contact, or when resection surgery is contraindicated ${ }^{49,50}$. Depth electrodes have also been used for less conventional indications, such as deep cerebral stimulation, for example in relation to subthalamic nuclei or mamillothalamic tract, thus finding a new scenario of action ${ }^{51,52}$.

Today, for research purposes, depth electrodes can be coupled to each other, as probes for microdialysis, thereby making it possible to examine the concentrations of substances of interest in the cerebrospinal fluid or cerebral tissue ${ }^{53}$.

For the future, research is being conducted towards constructing "smart" electrodes that already have their own built-in preamplifiers, analog-to-digital converters, wireless transmission and energy generators. Phase III studies are in progress, towards producing implantable devices that continually record cerebral electrical activity and provide electrical stimulation to interrupt crisis ac- tivity, through dept electrodes and subdural electrodes (Neuropace, La Jolla, CA, USA).

Therefore, there is an enormous future potential for increasing the applications of depth electrodes and SEEG, both for diagnostic use and for therapeutic use. Robotic systems for implanting depth electrodes, the constant evolution of imaging and computational techniques and the use of combined depth electrodes as probes for microdialysis open up the future possibility of even greater precision within the technique of depth electrode implantation and of widening the understanding of epileptogenic zones, with electrophysiological and biochemical data on this region. The brain stimulation of different deep targets and the construction of "smart" electrodes may soon increase the need for depth electrode implantation.

\section{REFERENCES}

1. Talairach L, Bancaud J. Stereotaxic approach to epilepsy. Arch Neurol Psychiatry 1951;65:272-290.

2. Olivier A, Gloor P, Quesney LF, Andermann F. The indications for and the role of depth electrode recording in epilepsy. Appl Neurophysiol 1983; 46:33-36.

3. Guenot M, Isnard J, Ryvlin P, et al. Neurophysiological monitoring for epilepsy surgery: the Talairach SEEG method. Stereoelectroencephalography. Indications, results, complications and therapeutic applications in a series of 100 consecutive cases. Stereotact Funct Neurosurg 2001;77:29-32.

4. van Veelen CW, Debets RM. Functional neurosurgery in the treatment of epilepsy in the Netherlands: aspects of presurgical evaluation and the contribution of subdural and stereotactically implanted depth electrodes in the Dutch Workgroup for Functional Surgery. Acta Neurochir (Wien) 1993;124:7-10.

5. Binnie CD, Elwes RD, Polkey CE, Volans A. Utility of stereo-electroencephalography in preoperative assessment of temporal lobe epilepsy. J Neurol Neurosurg Psychiatry 1994;57:58-65.

6. Lee KH, Park YD, King DW, et al. Prognostic implication of contralateral secondary electrographic seizures in temporal lobe epilepsy. Epilepsia 2000;41:1444-1449.

7. Blatt DR, Roper SN, Friedman WA. Invasive monitoring of limbic epilepsy using stereotactic depth and subdural strip electrodes: surgical technique. Surg Neurol 1997;48:74-79.

8. Spencer SS. Depth electroencephalography in selection of refractory epilepsy for surgery. Ann Neurol 1981;9:207-214.

9. Usui N, Mihara T, Baba K, et al. Intracranial EEG findings in patients with lesional lateral temporal lobe epilepsy. Epilepsy Res 2008;78:82-91.

10. Penfield $W$, Jasper $H$. Epilepsy and the functional anatomy of the human brain. Little Boston: Brown and Co; 1954.

11. Kirikae T, Wada J. Electrothalamogram of petit-mal seizures. Med Bioll 1951;20:253.

12. Spiegel EA, Wycis HT. Diencephalic mechanisms in petit-mal epilepsy. Electroencephalogr Clin Neurophysiol 1951;3:473-475.

13. Williams D, Parsons-Smith $\mathrm{G}$. The spontaneous electrical activity of the human thalamus. Brain 1949;72:450-482.

14. Jung R, Reichert T, Heines KD. Technique and value of operative electrocorticography and subcortical deduction of brain potentials. Nervenarzt 1951;22:433-436.

15. Dodge HW, Holman CB, Sem-Jacobsen CW, Bickford RG, Petersen MC. Technic of depth electrography. Mayo Clin Proc 1953;28:147-155.

16. Delgado JMR. Use of intracerebral electrodes in human patients. Electroencephalogr Clin Neurophysiol 1956;8:528-530.

17. Spiegel LA, Wycis HT, Marks M, Lee Al. Stereotaxic apparatus for operations on the human brain. Science 1947;106:349-350.

18. Spiegel LA, Wycis HT. Thalamic recordings in man with special reference to seizure discharges. Electroencephalogr Clin Neurophysiol 1950;2:23-39. 
19. Crandall PH, Walter RD, Rand RW. Clinical applications of studies on stereotactically implanted electrodes in temporal lobe epilepsy. J Neurosurg 1963;20:827-840

20. Bancaud J. Apport de l'explortation fonctionnelle par voie steréotax - ique à la chirurgie de l'epilepsie. Neurochirurgie 1959;5:55-112.

21. Bancaud J, Dell MB. Techniques et methodes de exploration fonctionnelle stèréotaxique des structures encéphaliques chez l'homme (cortex, souscortex, noyaux gris centraux). Rev Neurol 1939;101:220-221.

22. Talairach J, Bancaud J, Bonis A, Szikla G, Tornoux P. Functional stereotatic exploration of epilepsy. Confin Neurol 1962;22:328-331.

23. Bancaud J, Talairach J, Bonis A, et al. La stereo-electroencephalo-graphie dans epilepsie. Paris: Masson; 1965.

24. Talairach J, Bancaud J. Stereotaxic approach to epilepsy. Methodology of anatomo-functional stereotaxic investigations. Progr Neurol Surg 1973;5: 297-354.

25. Talairach J, Bancaud J, Szikla G, Bonis A, Geier S, Vedrenne C. Approche nouvelle de la neurochirugie de l'epilepsie. Méthodologie sterotaxique et resultats thérapeutiques. Neurochirurgie 1974;20(Suppl 1):S1-S240.

26. Talairach J, Tournoux J. Co-planar stereotaxic atlas of the human brain: Dimensional Proportional System: to approach lo cerebral imaging. StuttgartNew York: Georg Thieme Verlag; 1988.

27. Szikla G, Bouvier G. Hori T. In vivo localization of brain sulci by arteriography; a stereotactic anatomoradiological study. Brain Res 1975:95:497-502.

28. Szikla U, Bouvier G, Hori J, Petrov V. Angiography of the human brain cortex. Berlin: Springer; 1977.

29. Talairach J, Szikla G. Application of stereotactic concepts to the surgery of epilepsy. Acta Neurochir 1980;30(Suppl):S35-S54.

30. Heyman D, Menegalli-Boggelii D, Lajal Y. Adaptation ot the Talairach technique to the evolution of medical imaging. Stereotact Funct Neurosurg 1997:68:59-63.

31. Devaux B, Nataf F, Meder JF, Turak B, Merienne L. Prospects and future: evolution of stereotactic methodology for planning. Neurochirurgie 2001;47: 253-259.

32. Pecker J. Jean Talairach. Surg Neurol 1980:14:241-242.

33. Chauvel P. Contribution of Jean Talairach and Jean Bancaud to epilepsy surgery. In Lüders HO, Comair YG (Eds). Epilepsy Surgery. $2^{\text {nd }}$ ed. Philadelphia: Lippincott Wiliams \& Wilkins, 2001:35-41.

34. Davies KG, Philips BLB, Hermann BP. MRI confirmation of accuracy of freehand placement of mesial temporal lobe depth electrodes in the investigation of intractable epilepsy. Br J Neurosurg 1996:10:175-178.

35. Mehta AD, Labar D, Dean A, et al. Frameless stereotactic placement of depth electrodes in epilepsy surgery. J Neurosurg 2005;102:1040-1045.

36. Murphy MA, O'Brien TJ,Cook MJ. Insertion of depth electrodes with or without subdural grids using frameless stereotactic guidance systemstechnique and outcome. Br J Neurosurg 2002;16:119-125.

37. Song JK, Abou-Khalil, Konrad PE. Intraventricular monitoring for temporal lobe epilepsy: report on technique and initial results in eight patients. J Neurol Neurosurg Psychiatry 2003;74:561-565.
38. De Almeida AN, Olivier A, Quesney F, Dubeau F, Savard G, Andermann F. Efficacy of and morbidity associated with stereoelectroencephalography using computerized tomography or magnetic resonance imaging-guided electrode implantation. J Neurosurg 2006;104:483-487.

39. Engel JJ, Van Ness PC, Rasmussen TB, Ojemann LM. Outcome with respect to epileptic seizures. In Engel JJ (Ed). Surgical treatment of the epilepsies. New York: Raven Press; 1993:609-622.

40. Cossu M, Chabardès S, Hoffman D, Lo Russo G. Presurgical evaluation of intractable epilepsy using stereoelectroencephalography methodology: principles, technique and morbidity. Neurochirurgie 2008;54:367-373.

41. So N, Gloor P, Quesney LF, Jones-Gotman M, Olivier A, Andermann F. Depth electrode investigations in patients with bitemporal epileptiform abnormalities. Ann Neurol 1989;25:423-431.

42. Sansur CA, Frysinger RC, Pouratian N, et al. Incidence of symptomatic hemorrhage after stereotactic electrode placement. J Neurosurg 2007; 107:998-1003.

43. Cahan LD, Sutherling W, McCullough MA, Rausch R, Engel J Jr, Crandall PH. Review of the 20-year UCLA experience with surgery for epilepsy.Cleve Clin Q 1984:51:313-318.

44. Munari C. Depth electrode implantation at Höpital Sainte Anne, Paris. In: Engel JJ (Ed). Surgical treatment of the epilepsies. New York: Raven Press, 1987:583-588

45. Wyler AR, Walker G, Somes $G$. The morbidity of long term monitoring using subdural strip electrodes. J Neurosurg 1991;74:734-737.

46. Olivier A, Marchand E, Peters T, Tyler J. Depth implantation at the Montreal Neurological Institute and Hospital. In: Engel J Jr (Ed). Surgical treatment of the epilepsies. New York: Raven Press; 1987:595-601.

47. Espinosa J, Olivier A, Andermann F, Quesney F, Dubeau F, Savard G. Morbidity of chronic recording with intracranial depth electrodes in $170 \mathrm{pa}$ tients Stereotact Funct Neurosurg 1994;63:63-65.

48. Wieser HG, Schwarz U, Blättler T, et al. Serial EEG findings in sporadic and iatrogenic Creutzfeldt-Jakob disease. Clin Neurophysiol 2004;115 2467-2478.

49. Guenot M, Isnard J, Ryvlin P, Fischer C, Mauguière F, Sindou M. SEEG-guided RF thermocoagulation of epileptic foci: feasibility, safety, and preliminary results. Epilepsia 2004;45;1368-1374

50. Kameyama S, Murakami H, Masuda H, Sugiyama I. Minimally invasive magnetic resonance imaging-guided stereotactic radiofrequency thermocoagulation for epileptogenic hypothalamic hamartomas. Neurosurgery 2009; 65:438-449.

51. Dinner DS, Neme S, Nair D, et al. EEG and evoked potential recording from the subthalamic nucleus for deep brain stimulation of intractable epilepsy. Clin Neurophysiol 2002;113:1391-1402.

52. Khan S, Wright I, Javed S, et al. High frequency stimulation of the mamillothalamic tract for the treatment of resistant seizures associated with hypothalamic hamartoma. Epilepsia 2009:50:1608-1611.

53. Cavus I, Kasoff WS, Cassaday MP, et al. Extracellular metabolites in the cortex and hippocampus of epileptic patients. Ann Neurol 2005:57:226-235. 